\title{
Effect of Increase in Dialysate Bicarbonate Concentration on Acid-Base and Respiratory Status of Hemodialysis Patients
}

\author{
David Tovbin ${ }^{1 *}$, Jony Sheynin ${ }^{4 a, 4 b}$, Andrea Smeraglio ${ }^{5}$, Lone Avnon ${ }^{3}$ and Shimon Storch ${ }^{2}$ \\ ${ }^{1}$ Nephrology, Emek Medical Center \\ ${ }^{2}$ Bnai-Zion Medical Center (BZMC), Technion, Israel Institute of Technology, Israel \\ ${ }^{3}$ Pulmonary, Soroka University Medical Center (SMUC), Israel \\ ${ }^{4 a}$ Department of Psychiatry and Behavioral Science, Texas A\&M University Health Science Center, Houston, TX, USA (current affiliation) \\ ${ }^{4 b}$ Department of Biomedical Engineering, Ben-Gurion University of the Negev, Beer Sheva, Israel \\ ${ }^{5}$ Department of Internal Medicine, Portland Veterans, Administration Hospital, USA
}

*Corresponding author: David Tovbin, Department of Nephrology, Emek Medical Center Afula, Israel 18101 Technion, Israel

Institute of Technology, Haifa, Israel

\section{ARTICLE INFO}

Received: 㓞 June 27, 2019

Published: 幽 July 10, 2019

Citation: David Tovbin, Jony Sheynin, Andrea Ghena, Lone Avnon, Shimon Storch. Effect of Increase in Dialysate Bicarbonate Concentration on Acid-Base and Respiratory Status of Hemodialysis Patients. Biomed J Sci \& Tech Res 19(3)2019. BJSTR. MS.ID.003315.

Keywords: Bicarbonate; Dialysate; Metabolic Acidosis; Hemodialysis; Metabolic Alkalosis; Alkalemia; Hypercapnia

Abbreviations: HD: Hemodialysis; BIC: Bicarbonate; DBIC: Dialysate Bicarbonate Concentration; SBIC: Serum Bicarbonate Level; HDBIC: High Dialysate Bicarbonate Concentration; LDBIC: Low Dialysate Bicarbonate Concentration; MAC: Metabolic Acidosis; MAL: Metabolic Alkalosis; BZMC: Bnai-Zion Medical Center; SUMC: Soroka University Medical Center

\section{ABSTRACT}

Background: The appropriate hemodialysis dialysate bicarbonate concentration isn't clear. The recommended pre-hemodialysis blood bicarbonate level of $>22 \mathrm{mEq} / \mathrm{L}$ is frequently not achieved on the commonly used dialysate bicarbonate concentration of $33-35 \mathrm{mEq} / \mathrm{L}$. Higher dialysate bicarbonate concentration may correct acidosis and improve bone, muscle \& nutritional state. However, it may also induce intra-dialytic metabolic alkalosis/alkalemia and/or increase bicarbonate buffering and $\mathrm{CO} 2$ production inducing hypercapnia in patients with disturbed ventilation. Recently Higher dialysate bicarbonate concentration has been demonstrated to be associated with increased mortality.

Objectives: To evaluate the effects of high dialysate bicarbonate concentration on correction of acidosis in patients who were acidotic on low dialysate bicarbonate concentration, and on development of intradialytic metabolic alkalosis/alkalemia and/ or hypercapnia.

Methods: In a prospective bi-center study, nineteen chronic hemodialysis patients were evaluated on consecutive three-week period on low dialysate bicarbonate concentration (33-34mEq/L) and afterwards high dialysate bicarbonate concentration $(40 \mathrm{mEq} / \mathrm{L})$. Arterial blood gases and electrolytes were assessed once weekly at start, middle and end of first weekly hemodialysis.

Results: On low dialysate bicarbonate concentration pre-hemodialysis blood bicarbonate level was $21.8+3.3$ and $<22 \mathrm{mEq} / \mathrm{L}$ in 11 patients. High dialysate bicarbonate concentration in these patients raised pre- hemodialysis blood bicarbonate level to $26.6+5 \mathrm{mEq} / \mathrm{L}$ but induced intradialytic metabolic alkalosis/alkalemia similarly to the non-acidotic patients (post-hemodialysis: blood bicarbonate level $35.3+1.7 \mathrm{mEq} / \mathrm{L}$ vs $37+2.1 \mathrm{mEq} / \mathrm{L}$, pH $7.52+0.04$ vs $7.51+0.04$, respectively). There were no significant hypercapnic episodes.

Conclusion: high dialysate bicarbonate concentration corrected the significant and common metabolic acidosis on low dialysate bicarbonate concentration but induced asymptomatic intra-dialytic metabolic alkalosis/alkalemia. 


\section{Introduction}

The appropriate hemodialysis (HD) dialysate bicarbonate (BIC) concentration (DBIC) isn't clear. The common practical book "Handbook of Dialysis" suggests DBIC to be 35-40mEq/L [1]. The American National Kidney Foundations (NKF) Kidney Disease Outcomes Quality Initiative (KDOQI) guidelines recommend keeping pre-hemodialysis (Pre-HD) blood BIC levels above $22 \mathrm{mEq} / \mathrm{L}$ [2] and emphasize positive effects of correction of metabolic acidosis (MAC) on nutrition, muscles and bones [3]. The intermittent nature of HD obligates rapid intensive changes, including a high post dialysis SBIC in order to minimize the acidosis which develops afterwards during the inter-dialytic period. Though oral BIC administration was suggested for MAC correction [4], it may be ineffective in non-study conditions due to inadequate adherence and may not lead to muscle status improvement [5].

Therefore, high DBIC (HDBIC), which is not dependent on patients' adherence, may be required. However, as higher dialysate bicarbonate concentration became more prevalent, a large observation cohort study demonstrated that high dialysate bicarbonate concentration was associated with worse outcome especially in the more acidotic patients [6]. HDBIC may be associated with intra-dialytic and post-dialytic adverse events such as metabolic alkalosis (MAl)/alkalemia and hypercapnia. Intradialytic alkolosis/ alkalemia may be associated with augmented decrease in ionized calcium and hypokalemia [7-9]. HDBIC increases transfer from the dialysate into the blood of $\mathrm{CO}_{2}$ and $\mathrm{BIC}$, which is buffered by acids that are present before HD and organic acids produced during HD especially in states of reduced perfusion and hypoxia [10-13]. This may increase production of $\mathrm{CO}_{2}$ that is added to the transferred $\mathrm{CO}_{2}$, which are usually not associated with hypercapnia or hypoxemia $[14,15]$, but might induce intradialytic hypercapnia in the presence of ventilation disturbances [16,17].

It was suggested that a healthy ventilation response is needed to excrete the excess $\mathrm{CO}_{2}$ generated during BIC HD [18-20]. However, decreased ventilatory response to hypercapnia and frequent phrenic nerve neuropathy have been reported in HD patients [21,22]. In addition, respiratory problems are common in HD patients including pulmonary congestion and hypertension, chronic obstructive pulmonary disease (COPD) and sleep apnea syndrome (SAS) [23,24]. Many HD patients fall asleep during HD and in SAS related daytime somnolence this sleep may be associated with apneic episodes [25]. Opiate administration which may affect ventilation [26] is also common in HD patients due to frequency of severe chronic pain. Thus, we raised the concern that a potential adverse event of HDBC may be intradialytic hypercapnia. Thus, our objectives in this study were to assess effects of low and high DBIC on acid base-balance and respiration, in order to improve adjusting DBIC for different HD patients.

\section{Methods}

\section{Study Design: The Study is a Prospective Controlled Bi- Center Study}

\section{Patients}

19 chronic HD patients agreed to participate and were included in the study. Exclusion criteria were HD catheter, hepatitis B or C, infection, malignancy, recent surgery or hospitalization and unstable medical condition. Patients' demographic and co-morbidity characteristics are depicted. There were 12 males, seven females and eight diabetic patients. Patients' age range was 27-82 years. 11 patients were from SUMC and eight from BZMC. Pulmonary status included history of respiratory disease and smoking, chest X- Ray and information on symptoms; cough, dyspnea and daytime fatigue. The study was performed in Soroka University Medical Center (SUMC) and Bnai-Zion Medical Center (BZMC) during May 2006 to October 2007. Patients performed dialysis in their regular dialysis condition with a blood flow of 250-350 $\mathrm{ml} / \mathrm{min}$. F8HPS and in one patient F80 (Fresenius, Bad Hamburg, Germany) dialyzers were used In SUMC and Sureflux 190Gga (Nipro, Japan) in BZMC. Low calcium dialysate $2.5 \mathrm{mEq} / \mathrm{l}$ was used. Patients served as their own control. Each patient started with the current DBIC of $33-34 \mathrm{mEq} / \mathrm{L}$, transferred afterwards to higher concentration of $40 \mathrm{mEq} / \mathrm{L}$ and evaluated on each concentration for a period of three weeks. Blood gases and electrolytes ( $\mathrm{K}$ and ionic $\mathrm{Ca}$ ) were evaluated after 2-3 sessions on the evaluated DBIC.

Statistical Analysis: Nonparametric tests were used; Wilcoxon signed rank test for comparing paired data and Spearman test for assessing correlation.

\section{Results}

\section{Assessment on Low Dialysate BIC Concentration}

Patients' blood gases measurements on LDBIC are shown. Mean pre-HD SBIC was $21.2+8$ (range: 17.1-27.7)mEq/L. 11 patients were with pre-HD SBIC below the $22 \mathrm{mEq} / \mathrm{L}$ threshold recommended by NKF-KDOQI guidelines $(19.3+1.4$, range: 17.121) $\mathrm{mEq} / \mathrm{L}$ and were considered as suffering from significant MAC. The eight patients with pre-HD SBIC of 25.2+1.7 (range: 22.5-27.7) $\mathrm{mEq} / \mathrm{L}$ were considered as not suffering from significant MAC (NMAC) and not requiring HDBIC. At end of HD, Mac was corrected in almost all patients.

\section{Assessment on High Dialysate BIC Concentration}

Patients' blood gases measurements on HDBIC are shown. In the MAC patients, pre-HD SBIC was $26.6+5 \mathrm{mEq} / \mathrm{L}$ and only in two patients $<22(>21) \mathrm{mEq} / \mathrm{L}$. Post-HD SBIC was $35.3+1.7 \mathrm{mEq} / \mathrm{L}$ and in 8/11 patients $>35$ (range: $35.1-37.6) \mathrm{mEq} / \mathrm{L}$. Pre-HD $\mathrm{pCO}_{2}$ was 40.9+4.1 (range: $34-45.1$ ) mmHg. Post- $\mathrm{HD} \mathrm{pCO}_{2}$ was $42.9+5$ (range: 
35.9-50.4) $\mathrm{mmHg}$ and in $10 / 11$ patients $<50 \mathrm{mmHg}$. Post-HD pH was $7.52+0.04$ and in $7 / 11$ patients $>7.5$ (range: 7.51-7.58). HD $\mathrm{pCO}_{2}$ change/ HD SBIC change was $0.23+0.45$ (range:(-0.3)-1.4), while the normal in MAl is 0.7. In the NMAC patients, pre-HD SBIC was $30.9+4.9$ (range: $25.9-38.7$ ) $\mathrm{mEq} /$ Land only in $2 / 8$ patients $<27 \mathrm{mEq} / \mathrm{L}$. Post-HD SBIC was $37+2.1$ (range: $35.2-40.8$ ) $\mathrm{mEq} / \mathrm{L}$. Pre-HD $\mathrm{pCO}_{2}$ was 42.5+4.2 (range: 34.9-47.7) mmHg. PreHD pH was 7.42+0.05 (range: 7.34-7.47). Post-HD pH was 7.51+0.04 (range: 7.41-7.55) and in 6/8 patients $>7.5$, post- $\mathrm{HD} \mathrm{pCO}_{2}$ was $45.5+5.6$ (range: $38-54.5$ ) $\mathrm{mmHg}$ and in $8 / 9$ patients $<50 \mathrm{mmHg}$.

$\mathrm{HD} \mathrm{pCO}_{2}$ change/HD SBIC change was $0.71+1.2$ (range:(-0.77)-2.82).HDBIC was associated with correction of preHD acidosis in the MAC patients with a development of pre-HD MAl in the NMAC patients (Figure 1). However, HDBIC induced post-HD
MAl in both patient groups (Figure 2). In addition, on HDBIC there was a negative correlation between $\triangle$ SBIC to pre-HD BIC (Figure 3), resulting in the non-significant difference in post-HD SBIC between the NMAC and MAC patients. Moreover, on HDBIC there was a positive correlation between post-HD $\mathrm{pCO}_{2}$ and pre-HD BIC, and a negative correlation between post-HD $\mathrm{pH}$ and pre-HD SBIC was close to statistical significance $(\mathrm{P}=0.07)$. $\mathrm{HD} \mathrm{pCO}_{2}$ change/HD SBIC change was low in all patients explaining the relatively low post-HD $\mathrm{pCO}_{2}$. There was no correlation between post-HD $\mathrm{pCO}_{2}$ and post-HD $\mathrm{pO}_{2}$. However, in patients with post-HD $\mathrm{pO}_{2}$ below 95 mmHg who comprised half of the patients, $\mathrm{pCO}_{2}$ was significantly negatively correlated with $\mathrm{pO}_{2}(\mathrm{P}<0.05)$. HDBIC wasn't associated with symptomatic episodes of hypocalcemia and potassium or blood pressure changes.

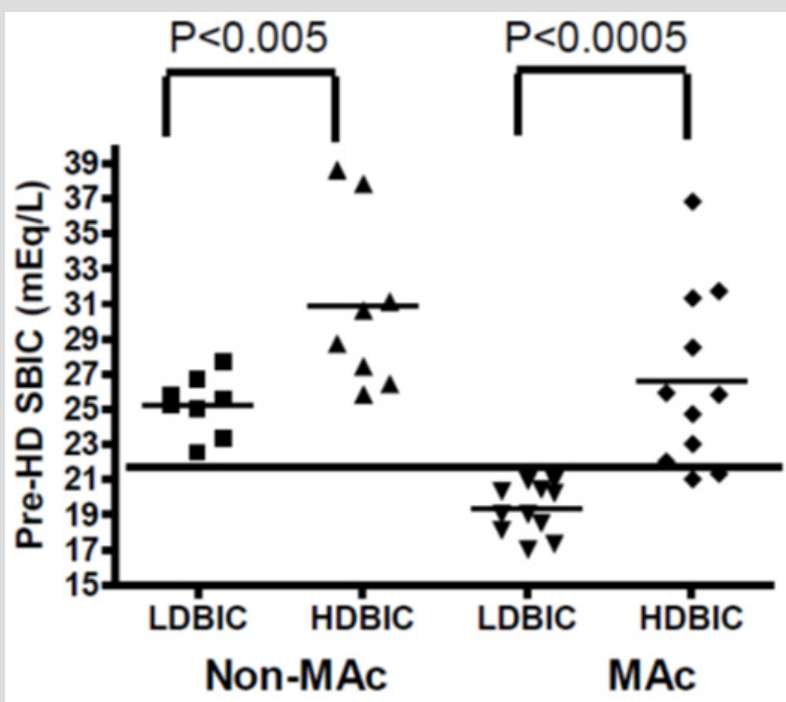

Figure 1: Pre-HD SBIC on LDBIC and HDBIC, HD- hemodialysis, SBIC- serum bicarbonate, LDBIC- low dialysate bicarbonate concentration HDBIC- high dialysate bicarbonate concentration, MAC- metabolic acidosis, NMAC- no metabolic acidosis.

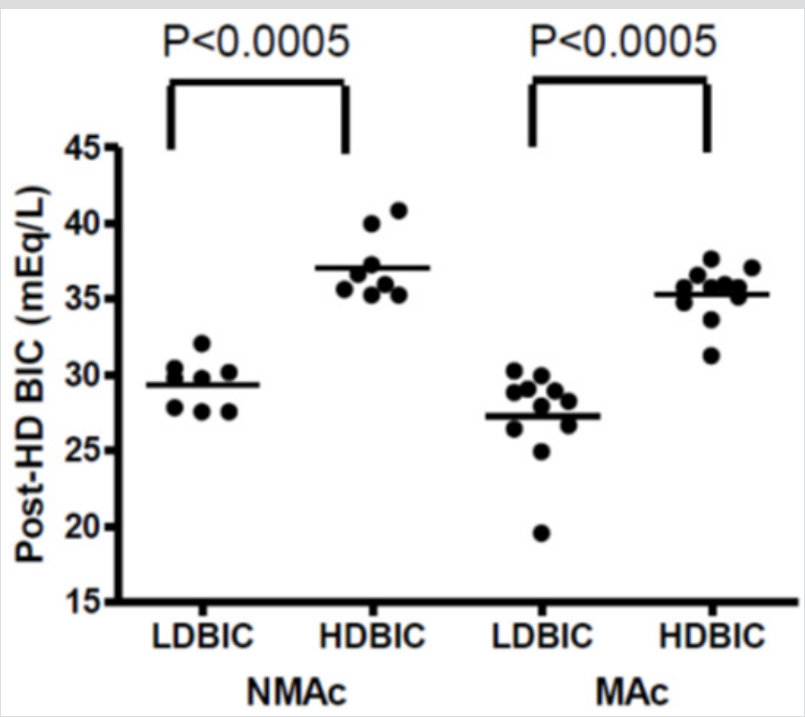

Figure 2: Post-HD SBIC on LDBIC and HDBIC, HD- hemodialysis, SBIC- serum bicarbonate, LDBIC- low dialysate bicarbonate concentration, HDBIC- high dialysate bicarbonate concentration, MAC- metabolic acidosis, NMAC- no metabolic acidosis. 


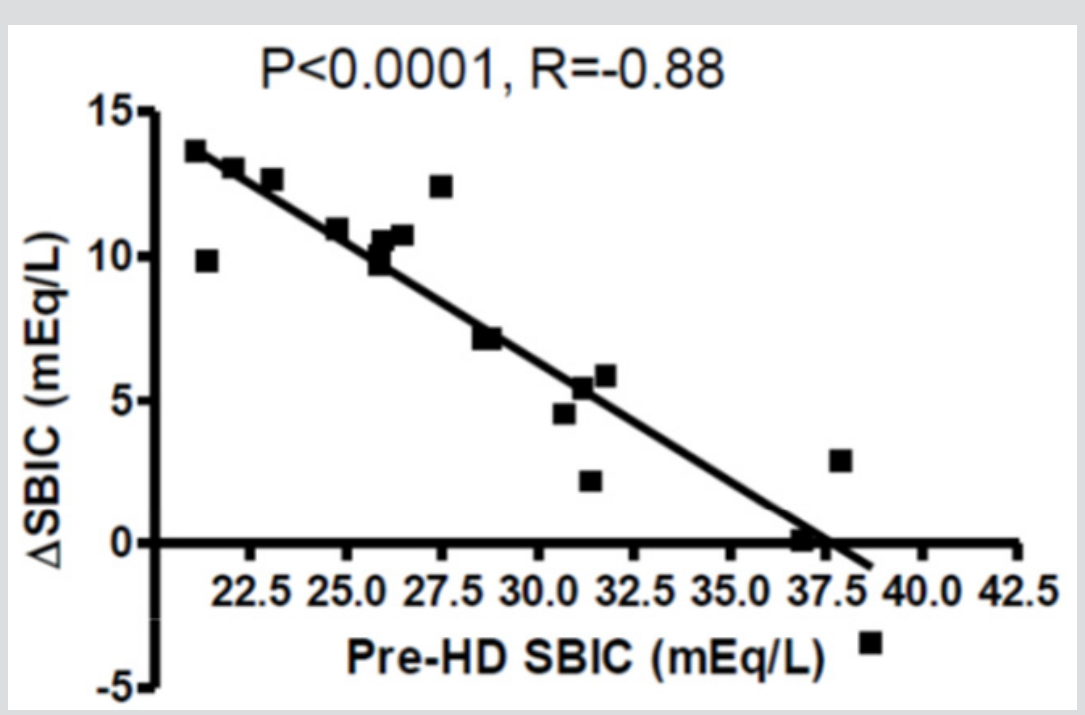

Figure 3: Correlation of $\triangle$ SBIC to Pre-HD SBIC on HDBIC, HD- hemodialysis, SBIC- serum bicarbonate, HDBIC- high dialysate bicarbonate concentration.

\section{Discussion}

This study assessed acid-base and respiratory status of HD patients on two different DBIC. We assumed that HDBIC is essential for patients with pre-HD MAC, since it may correct MAC and its adverse effects on bones, muscles, nutritional status and well-being $[3,4]$. However, we were aware that HDBIC may induce intradialytic alkalemia [8]. We also raised the concern that HDBIC induced increased $\mathrm{CO}_{2}$ transfer and production may lead to hypercapnia in the presence of ventilatory disturbances, which are frequent in HD patients. As expected, many of the studied patients suffered from MAC on the routine LDBIC which was corrected by HDBIC, and thus may benefit from HDBIC. In the patients who didn't need HDBIC, it also induced pre-HD MAl. We also expected that those patients who started with lower pre-HD SBIC on LDBIC will not reach the high post-HD SBIC levels as the patients who were not acidotic on LDBIC and will be protected from post-HD MAl/alkalemia.

SBIC increase during HDBIC was significantly negatively correlated with pre- HD BIC as expected, but surprisingly to such an extent that pre-HD SBIC didn't correlate with post-HD SBIC, which was similar in both patients' groups. Moreover, not only that the acidotic patients are not protected from intradialytic alkalosis, on HDBIC post-HD $\mathrm{pCO}_{2}$ was negatively correlated with pre-HD SBIC. Thus, patients with lower pre-HD SBIC on HDBIC increased their SBIC dramatically but remained with lower post-HD $\mathrm{pCO}_{2}$ and tendency to increased alkalemia. This may be explained by the limited degree of respiratory compensation to MAl as observed in acute BIC administration [27], and a lag in compensatory hypercapnia to MAl when it evolves rapidly. There were no episodes of clinically significant hypercapnia. We previously reported intradialytic hypercapnia on routinely used DBIC and similar case was reported afterwards. Both patients were morbidly obese chronic HD patients with decreased ventilation reserve in acute unstable condition of pulmonary infection and increased BIC buffering due to sepsis, low tissue perfusion or hypoxemia $[9,28]$.

In such patient's lower dialysate bicarbonate, non- invasive positive pressure ventilation and inter-dialytic oral bicarbonate administration is required $[9,28,29]$. However, though some of the studied patients had pulmonary disturbances, unstable or infected patients were excluded from the study, and this may explain the absence of severe intra-dialytic hypercapnia. In conclusion, HDBIC corrected the significant and common MAC on LDBIC, but induced asymptomatic intra-dialytic MAl/alkalemia associated with decreased compensatory hypercapnia and no severe hypercapnic episodes. Individual and gradual increase in DBIC evaluating post-HD SBIC, $\mathrm{pH}, \mathrm{pCO}_{2}, \mathrm{pO}_{2}$ and electrolytes is probably required in acidotic HD patients on LDBIC. A new approach of utilizing a variable dialysate bicarbonate starting with initially high dialysate bicarbonate levels with a subsequent exponential decline, needs to evaluate [30].

\section{References}

1. Daugirdas JT, Blake PG, Ing TS (2016) “Handbook of Dialysis”. Lippincott, Williams and Wilkins, Philadelphia, PA, USA.

2. (2001) I NKF-K/DOQI Clinical Practice Guidelines for Hemodialysis Adequacy: update 2000. Am J Kidney Dis 37(1 Suppl 1): S7-S64.

3. Mehrotra R, Kopple JD, Wolfson M (2003) Metabolic acidosis in maintenance dialysis patients: Clinical considerations. Kidney Int Suppl (88): S13-25.

4. Movilli E, Gaggia P, Camerini C, Brunori G, Vizzardi V, et al. (2005) Effect of oral sodium bicarbonate supplementation on interdialytic weight gain, plasma sodium concentrations and predialysis blood pressure in hemodialysis patients. Blood Purif 23(5): 379-383.

5. Ruggier F, Caso G, Wegmann M, McNurlan MA, Wahl C Imoberdorf R, et al. (2009) Does increasing blood pH stimulate protein synthesis in dialysis patients? Nephron Clin Pract 112(4): c276-283.

6. Tentori F, Karaboyas A, Robinson B, Morgenstern H, Zhang J, et al. (2013) Association of dialysate bicarbonate concentration with mortality in the 
Dialysis Outcomes and Practice Patterns Study (DOPPS). Am J Kidney Dis 62(4): 738-746.

7. Heguilen RM, Sciurano C, Bellusci AD, Fried P, Mittelman G, et al. (2005) The faster potassium-lowering effect of high dialysate bicarbonate concentrations in chronic haemodialysis patients. Nephrol Dial Transplant 20(3): 591-597.

8. Gabutti L, Ferrari N, Giudici G, Mombelli G, Marone C (2003) Unexpected haemodynamic instability associated with standard bicarbonate haemodialysis. Nephrol Dial Transplant 18(11): 2369-2376.

9. Tovbin D, Heimer D, Mashal A, Degtyar P, Avnon LS (2001) Clinical Study Intra- dialytic hypercapnic respiratory failure managed by noninvasive assisted ventilation. Am J Nephrol 21: 383-385.

10. Gennari FJ (1996) Acid-base homeostasis in end stage renal disease. Semin Dial 9(5): 404-411.

11. Ward RA, Wathen RL, Williams TE, Harding GB (1987) Hemodialysate composition and intradialytic metabolic, acid base and potassium changes. Kidney Int 32(1): 129-135.

12. Gotch FA, Sargant JA, Keen ML (1982) Hydrogen ion balance in dialysis therapy. Artif Organs 6(4): 388-395

13. Hood VL, Schubert C, Keller U, Muller S (1988) Effect of systemic pH on $\mathrm{pHi}$ and lactic acidosis generation in exhaustive forearm exercise. Am J Physiol 255(3 Pt 2): F479-F485.

14. Oettinger CW, Oliver JC (1993) Normalization of uremic acidosis in hemodialysis patients with high bicarbonate dialysate. J Am Soc Nephrol 3(11): 1804-1807.

15. Kobrin SM, Raja RM (1989) Effect of varying dialysate bicarbonate concentrations on serum phosphate. Trans Am Soc Artif Intern Organs 35(3): 423-426.

16. Haung CC, TsaiYH, Lin MC, Hsieh MJ, Lan RS, et al. (1997) Respiratory drive and pulmonary mechanics during haemodialysis with ultrafiltration in ventilated patients. Anaesth Intensive Care 25(5): 464-470.

17. Haung CC, Lin MC, Yang CT, Lan RS, Tsai YH, et al. (1998) Oxygen, arteria blood gases and ventilation are unchanged during dialysis in patients. JRespir Med 92(3): 534-540

ISSN: 2574-1241

DOI: 10.26717/BJSTR.2019.19.003315

David Tovbin. Biomed J Sci \& Tech Res

This work is licensed under Creative

Commons Attribution 4.0 License

Submission Link: https://biomedres.us/submit-manuscript.php
18. Sombolos KI, Bamichas GI, Christidou FN, Gionanlis LD, Karagianni AC, et al. (2005) $\mathrm{pO}_{2}$ and $\mathrm{pCO}_{2}$ increment in post-dialyzer blood: the role of dialysate. Artif Organs 29(11): 892-898.

19. Gotch FA, Sargent JA, Keen ML (1982) Hydrogen ion balance in dialysis therapy. Artif Organs 6(4): 388-395.

20. Symreng T, Flanigan MI, Lim VS (1992) Ventilatory and metabolic changes during high efficiency hemodialysis. Kidney Int 41(4): 10641069.

21. Auinger M, Wanke T, Merkle M, Lahrmann H, Kastenbauer T, et al. (1995) Effect of autonomic neuropathy on ventilatory response to progressive hypercapnia in dialysis patients. Nephrol Dial Transplant 10(6): 825830

22. Zifko U, Auinger M, Albrecht G, Kastenbauer T, Lahrmann H, et al. (1995) Phrenic neuropathy in chronic renal failure. Thorax 50(7): 793-794.

23.Zoccali C, Mallamaci F, Tripepi G (2001) Sleep apnea in renal patients. J Am Soc. Nephrol 12(12): 2854-2859.

24. Kimmel PL, Miller G, Mendelson WB (1989) Sleep apnea syndrome in chronic renal disease. Am J Med 86: 308-314.

25. Benz RL, Pressman MR, Hovick ET, Peterson DD (1999) A preliminary study of the effects of correction of anemia with recombinant human erythropoietin therapy on sleep, sleep disorders, and daytime sleepiness in hemodialysis patients (The SLEEPO study). Am J Kidney Dis 34(6): 1089-1095.

26. McQueen DS (1983) Opioid peptide interactions with respiratory and circulatory systems. Br Med Bull 39(1): 77-82.

27. Carlos R, Palacios F, Altayeh A, Qian Q (2011) Acute hypercapnic respiratory failure associated with hemodialysis. Dialysis \& Transplantation 40(2): 83-85.

28. Roberts Ke, Poppell Jw, Randall Ht, Vanamee P (1957) Respiratory alkalosis. Ann N Y Acad Sci 66(4): 955-965.

29. Tovbin D (2019) Hypercapnia in Hemodialysis (HD). AUN 1(2): 1-2.

30. Tovbin D, Sherman RA (2016) Correcting acidosis during hemodialysis: Current limitations and a potential solution. Semin Dial 29(1): 35-38.

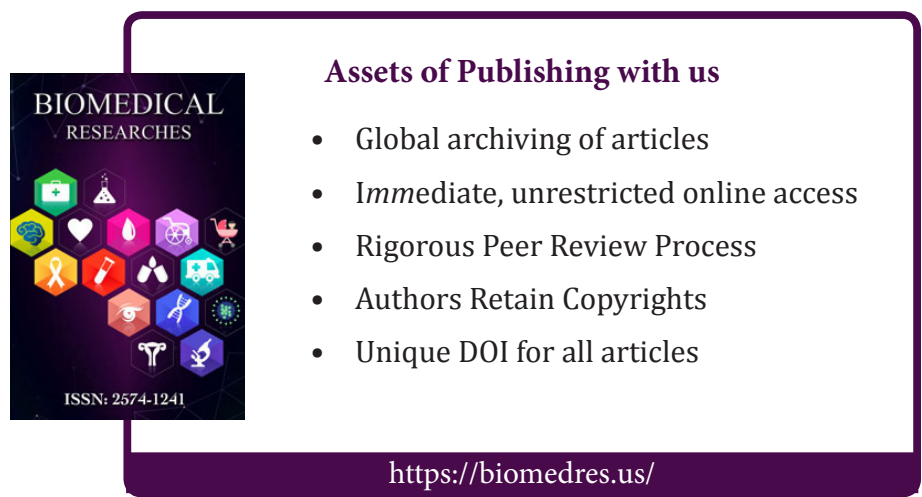

